\title{
A Comparative Study of Reactive Hyperemia in Human Forearm Skin and Muscle
}

\author{
G. ADDOR ${ }^{1}$, A. DELACHAUX ${ }^{1}$, B. DISCHL ${ }^{1}$, D. HAYOZ ${ }^{2}$, L. LIAUDET ${ }^{3}$, B. WAEBER ${ }^{1}$, \\ F. FEIHL ${ }^{1}$
}

${ }^{1}$ Division de Physiopathologie Clinique, Département de Médecine, ${ }^{2}$ Service d'Angiologie, Département de Médecine and ${ }^{3}$ Service de Médecine Intensive Adulte, Centre Hospitalier Universitaire Vaudois (CHUV), Lausanne, Switzerland

Received February 22, 2007

Accepted July 11, 2007

On-line October 11, 2007

\begin{abstract}
Summary
Reactive hyperemia (RH) in forearm muscle or skin microcirculation has been considered as a surrogate endpoint in clinical studies of cardiovascular disease. We evaluated two potential confounders that might limit such use of $\mathrm{RH}$, namely laterality of measurement and intake of non-steroidal anti-inflammatory drugs (NSAIDS). Twenty-three young non-smoking healthy adults were enrolled. In Experiment $1(n=16)$, the RH elicited by 3 min of ischemia was recorded in the muscle (strain gauge plethysmography, hand excluded) and skin (laser Doppler imaging) of both forearms. In Experiment $2(n=7), R H$ was determined in the dominant forearm only, one hour following oral acetylsalicylic acid $(1 \mathrm{~g})$ or placebo. In Experiment 1, peak RH was identical in both forearms, and so were the corresponding durations of responses. RH lasted significantly less in muscle than in skin $(p=0.003)$, a hitherto unrecognized fact. In the skin, acetylsalicylate reduced duration (43 vs. $57.4 \mathrm{~s}$ for placebo, $p=0.03$ ), without affecting the peak response. In muscle, duration tended to decrease with acetylsalicylate (21.4 vs. $26.0 \mathrm{~s}$ with placebo, $\mathrm{p}=0.06$ ) and the peak increase in blood flow was blunted (27.2 vs. $32.4 \mathrm{ml} / \mathrm{min} / 100 \mathrm{ml}$ tissue with placebo, $\mathrm{p}=0.003$ ). We conclude that, when using $\mathrm{RH}$ as a surrogate endpoint in studies of cardiovascular disease, a confounding by laterality of measurement need not be feared, but NSAIDS may have an influence, although perhaps not on the peak response in the skin.
\end{abstract}

\section{Key words}

Vasodilation - Ischemia - Laser Doppler - Strain gauge plethysmography • Surrogate endpoint • Acetylsalicylate

\section{Corresponding author}

François Feihl, Division of Clinical Pathophysiology, Lausanne University Hospital, PPA, BH10-701, CHUV, 1011 Lausanne, Switzerland. E-mail: Francois.Feihl@chuv.ch

\section{Introduction}

Cardiovascular diseases are presently a major cause of morbidity and death worldwide. Intervention trials focusing on so-called "hard" end-points, i.e. events such as an occurrence of stroke, acute myocardial infarction, newly diagnosed heart failure, or death are usually both extremely expensive and technically complicated, requiring the inclusion of huge number of patients observed over several years in order to achieve sufficient power (Williams 2005). In addition, it has been pointed out that the aforementioned endpoints lack both specificity and sensitivity when evaluating the efficacy of potential new therapies or prevention strategies (Cohn 2004). For these reasons, a substantial effort has been directed at identifying surrogate endpoints for cardiovascular disease, i.e. markers that would be linked to underlying pathophysiological events, thus reflecting disease progression and obviating the need to wait for the occurrence of clinical events, at least in trials designed to test for the efficacy of an intervention.

Numerous surrogate endpoints have been proposed (Cohn et al. 2004, Mancini et al. 2004). For some invasive maneuvers are required, examples being the assessment of endothelial function from the vasodilation induced by an intra-arterial infusion of acetylcholine into the coronary or forearm circulation. Other surrogate endpoints are accessible non-invasively, such as flow-induced vasodilation of the brachial artery, or the carotid intima-media thickness ratio, which can both be determined with ultrasonic techniques. The 
assessment of such non-invasively available endpoints requires considerable technical skills and/or shows substantial operator dependence, which constitutes an obstacle to large scale usage in trials or epidemiological studies. One exception is the evaluation of reactive hyperemia, i.e. the transient increase of blood flow above resting level observed after a short period of ischemia. Reactive hyperemia is dependent on the post-ischemic dilation of resistance arterioles. It is easily assessed in limbs, where ischemia can be started and terminated very simply by the inflation above systolic pressure, followed a few minutes later by deflation of a proximally placed pneumatic cuff. In these conditions, limb blood flow can be measured serially with strain gauge plethysmography, a method that in the forearm essentially reflects perfusion to skeletal muscle if care is taken to exclude the hand circulation in the course of assessment. Alternatively, microvascular skin blood flow can be recorded at a site distal to the cuff with laser Doppler flowmetry. Both strain gauge plethysmography and laser Doppler flowmetry are noninvasive, do not require a high level of training, and produce results essentially independent of the operator.

Whether assessed in forearm muscle (Sanada et al. 2002) or skin (Binggeli et al. 2003), reactive hypermia was diminished in hypercholesterolemic subjects in comparison with normocholesterolemic ones. In 862 healthy women, Vuilleumier et al. (2002) found that the peak reactive hyperemic response in forearm skin was negatively correlated with the Framingham risk score. The duration of reactive hyperemia in foreram muscle decreased with the accumulation of risk factors in 449 subjects devoid of overt cardiovascular disease (Ishibashi et al. 2006). Forearm skin reactive hyperemia was blunted in type 1 and type 2 diabetics (Tur et al. 1991, Skrha et al. 2001), and so was its muscle counterpart in patients with heart failure (Hirooka et al. 1994) or in those who later developed restenosis following coronary angioplasty (Wu et al. 2000). Taken together, these observations support reactive hyperemia as a potentially useful marker of cardiovascular disease.

It is noteworthy that none of these clinical studies specified which forearm was used for assessing reactive hyperemia. At least in the muscular vascular bed, it is conceivable that the response could differ between the dominant and non-dominant arm. In 16 young healthy adults, Carlsson et al. (1987) found that muscular reactive hyperemia was on the average $20 \%$ greater in the right than in the left forearm, but did not report whether any of these subjects were left-handed. We were unable to locate any other study concerning the effects of laterality on forearm reactive hyperemia. It would be important to clear this methodological point if these vascular responses are to be used for investigational purposes. The first aim of the present study was therefore to investigate possible systematic differences between the dominant and non dominant forearm regarding reactive hyperemia in muscle and skin.

It is known that forearm muscle reactive hyperemia in humans can be blunted by non steroidal antiinflammatory drugs (NSAID) (Kilbom and Wennmalm 1976, Carlsson and Wennmalm 1983, Carlsson et al. 1987, Engelke et al. 1996), indicating a partial dependence on metabolites of the cyclo-oxygenase (COX) pathway. Whether prostanoids also act as mediators of this response in human skin is less clear in view of contradictory reports indicating either no effect (Moppett et al. 2003, Dalle-Ave et al. 2004) or some inhibition by NSAIDs (Carlsson et al. 1983, Bisgaard et al. 1986, Binggeli et al. 2003). This point is relevant to the use of reactive hyperemia as a surrogate endpoint for cardiovascular disease, in view of the widespread intake of NSAIDs in the general population (Andersson et al. 1999). Therefore, our second aim was to compare the effects of COX inhibition on forearm skin and muscle reactive hyperemia in healthy humans.

\section{Methods}

\section{Subjects}

A total of 23 lean male non-smoking volunteers aged 18-30 years were studied. Medical history was unremarkable in all, and none had been on any medication for the month preceding the investigation. Approval was obtained from our Institutional Review Board for Human Experimentation. All subjects gave their informed consent in written.

\section{Reactive hyperemia}

A standard size pneumatic cuff was placed around the upper arm. Following baseline measurement of either skin or muscle blood flow in the corresponding forearm (see below for details of blood flow measurements), the upper arm cuff was inflated for $3 \mathrm{~min}$ to a pressure of $200 \mathrm{~mm} \mathrm{Hg}$ (i.e. largely above systolic), in order to achieve occlusion of arterial inflow, and then deflated, by means of an EC20 rapid cuff inflator (Hokanson, Bellevue, WA, USA). 


\section{Measurement of forearm muscle blood flow}

The hand was excluded from the circulation by inflation above systolic pressure of a pediatric blood pressure cuff placed around the wrist. In such conditions, the arterial inflow to the forearm, as provided by venous occlusion strain gauge plethymography, essentially represents blood flow to skeletal muscle. Venous occlusion was accomplished by means of the upper arm cuff, again inflated with the EC20 inflator, to a pressure of $40 \mathrm{mmHg}$ for $6 \mathrm{~s}$. The rate of increase in forearm volume in the course of venous occlusion was measured with a mercury strain gauge (Hokanson No. 20 or 22, depending on forearm size) connected to a TL100 plethysmograph (Hokanson). The generated analog signal was digitized with a Powerlab ML880 system (ADInstruments, Spechbach, Germany), visualized online for quality control (checking in particular for the presence of cardiogenic oscillations, which are required for data validity) and stored on computer disk for later processing. The Powerlab system also controlled the rapid cuff inflator, such that venous occlusions took place at regular 12-s intervals, starting $6 \mathrm{~s}$ after release of arterial occlusion. Blood flow was expressed in $\mathrm{ml}$ per minute and per $100 \mathrm{ml}$ of tissue volume.

\section{Measurement of forearm skin blood flow}

A laser Doppler Imager (LDI, Moor Instruments, Axminster, UK) was used to measure dermal blood flow within a $0.5 \times 2 \mathrm{~cm}$ area of distal forearm skin (at approximately $5 \mathrm{~cm}$ from the wrist), as previously described in this laboratory (Kubli et al. 2000, Pellaton et al. 2002, Boegli et al. 2003). Flow measurements, each lasting $2 \mathrm{~s}$, were repeated at regular 5-s intervals, starting immediately after release of arterial occlusion. Erythrocyte flux was expressed in Perfusion Units (PU), as usual with laser Doppler flowmetry.

\section{Protocols}

The study was approved by the Institutional Review Board on Human Experimentation at the University of Lausanne. The participants gave their informed consent in written. They were asked to not to take any antiinflammatory drugs in the week, and not to drink any coffee in the $12 \mathrm{~h}$, which preceded the study. All experiments took place between 4 and 6 p.m., in a quiet, temperature-controlled room $\left(23-24^{\circ} \mathrm{C}\right)$, with the subject lying supine on a hospital bed.

\section{Timing of measurements}

In all experiments, measurements of post- occlusive blood flow were carried out in triplicate in skin, and then in triplicate in muscle, or in the reversed order according to a randomization scheme. It was not feasible to simultaneously explore both territories, because small forearm movements generated by the repeated cuff inflations inherent to plethysmography would have interfered with laser Doppler flowmetry. Allowing for $5 \mathrm{~min}$ of restored blood flow before the next arterial occlusion (which lasted $3 \mathrm{~min}$ as stated above), one triplicate recording of reactive hyperemia in one territory took $25 \mathrm{~min}$.

\section{Experiment 1}

This experiment was designed to test for a possible systematic effect of laterality on the reactive hyperemic response of forearm skin and muscle. Sixteen subjects were studied on two occasions 1 to 3 days apart. On the first visit, muscle reactive hyperemia was recorded in one forearm, and skin muscle hyperemia in the other. Laterality of measurements was reversed on the second visit. Care was taken to assess skin blood flow at the same distance from the wrist on both forearms.

\section{Experiment 2}

This experiment was designed to evaluate the impact COX blockade on the reactive hyperemic response of forearm skin and muscle. Seven subjects were studied on two occasions 7 to 10 days apart. Reactive hyperemia was assessed in the dominant forearm only. On the first visit, the exact location of the site for skin blood flow measurement was marked on a transparent acetate film, together with the anatomical outline of the forearm, taking care to precisely reproduce the position of the distal skin fold marking the limit of the wrist. In this way, the same skin site could be probed on the second visit, thus removing one source of experimental variation.

The subject ingested $1.8 \mathrm{~g}$ of lysine

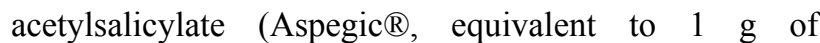
acetylsalicylate) dissolved in $125 \mathrm{ml}$ orange juice on one visit, and the same volume of orange juice alone on the other visit, in a randomized order. This dose of acetylsalicylate has been shown in our laboratory to block COX-dependent dermal microvascular vascular responses, with an efficiency maintained between $30 \mathrm{~min}$ and $2 \mathrm{~h}$ following administration (Golay et al. 2004). Skin and muscle reactive hyperemia were determined in triplicate within the second hour after ingestion. 

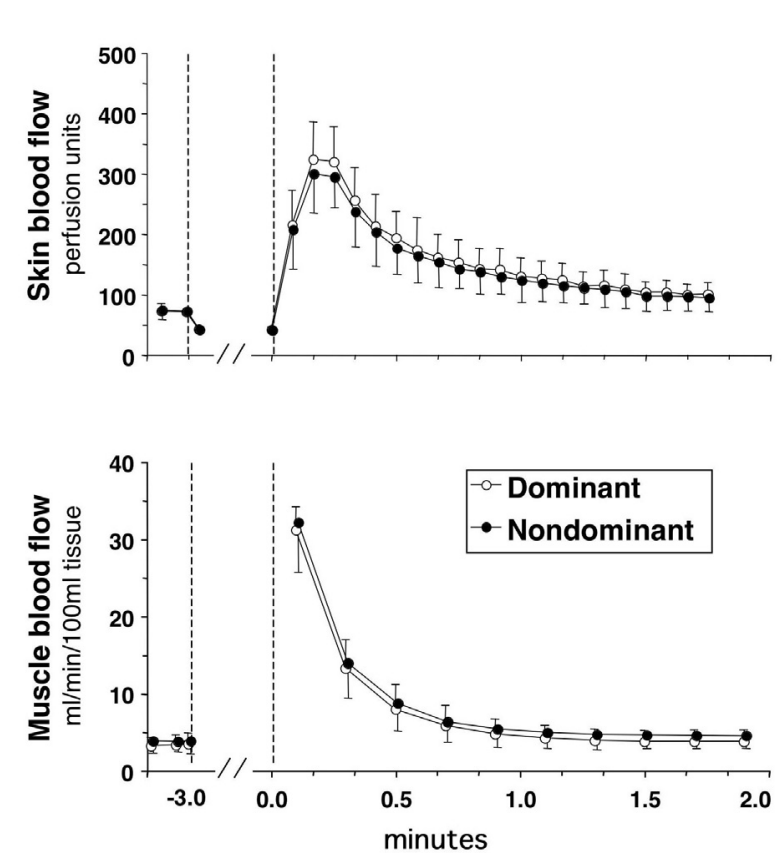

Fig. 1. Time course of reactive hyperemia induced by $3 \mathrm{~min}$ of ischemia (dashed vertical lines) in skin and muscle, evaluated in the dominant and non-dominant arm of 16 healthy subjects. Data are means \pm S.D.

The time course of each reactive hyperemic response was summarized as 1) the peak increase of blood flow above the baseline value measured immediately before arterial occlusion, and 2) the duration of hyperemia, calculated from the release of arterial occlusion to the time when the increase of blood flow above baseline became less than $25 \%$ of its peak value. No systematic effect the order of measurement within one series of triplicate was apparent from the data. Therefore, values of parameters derived from individual reactive hyperemia were averaged within triplicates. Then, statistical comparisons between responses obtained from the dominant and non-dominant arm (Experiment 1) or recorded after placebo and acetylsalicylate ingestion (Experiment 2) were carried out with paired t-tests, at an alpha level of 0.05. Data were summarized as mean $\pm \mathrm{SD}$.

\section{Results}

\section{Experiment 1}

The mean time courses of skin and muscle blood flow following $3 \mathrm{~min}$ of ischemia are shown in Figure 1. There were no differences between the dominant and non-dominant forearm. A striking feature was the much longer duration of reactive hyperemia in the skin as compared to the response in muscle. These visual

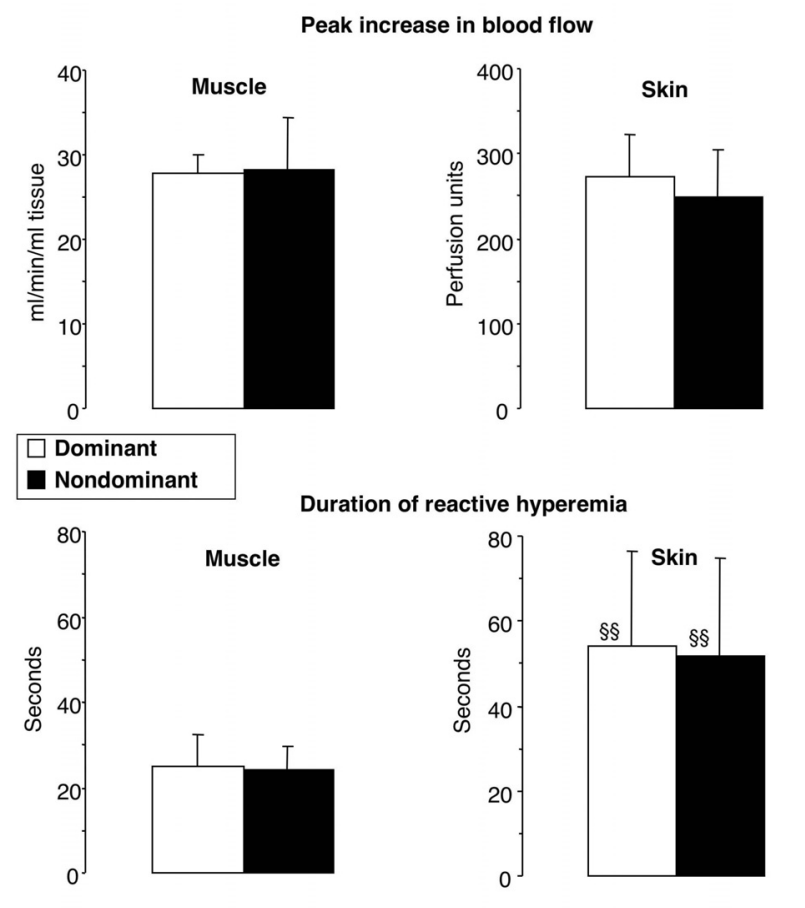

Fig. 2. Summary measures of reactive hyperemia induced by 3 min of ischemia in skin and muscle, evaluated in the dominant and non-dominant arm of 16 healthy subjects. ${ }^{\S} p<0.01$ duration in skin vs. duration in muscle. Data are means \pm S.D.

impressions conveyed by Figure 1 are quantified in Figure 2. The peak responses were practically identical in both forearms (muscle $27.8 \pm 2.2$ and $28.3 \pm 6.0 \mathrm{ml} / \mathrm{min} / 100$ $\mathrm{ml}$ tissue $\mathrm{p}=0.75$, skin $272 \pm 50$ and $249 \pm 55$ perfusion units $\mathrm{p}=0.14$, on respectively the dominant and non dominant sides), and so were the corresponding durations (muscle $24.8 \pm 7.7$ and $24.2 \pm 5.7 \mathrm{~s}, \mathrm{p}=0.75$, skin $54.1 \pm 22.4$ and $51.8 \pm 23.1 \mathrm{~s}, \mathrm{p}=0.66)$. The difference in duration between reactive hyperemia in muscle and skin was highly significant $(\mathrm{p}=0.003)$.

\section{Experiment 2}

Figure 3 depicts the mean time courses of reactive hyperemia in skin and muscle of the dominant forearm, following the ingestion of either $1 \mathrm{~g}$ acetylsalicylate or placebo, and the corresponding quantitations are shown in Figure 4. In the skin, COX blockade resulted in a somewhat shorter duration of hyperemia (acetylsalicylate 43.2 vs. placebo $57.4 \mathrm{~s}$, $\mathrm{p}=0.03$ ), without affecting the peak response (acetylsalicylate 286 vs. placebo 295 perfusion units, $\mathrm{p}=0.75)$. In forearm muscle, duration tended to decrease with acetylsalicylate (21.4 vs. $26.0 \mathrm{~s}$ with placebo, $\mathrm{p}=0.06$ ) and the peak increase in blood flow was significantly blunted (27.2 vs. $32.4 \mathrm{ml} / \mathrm{min} / 100 \mathrm{ml}$ tissue 


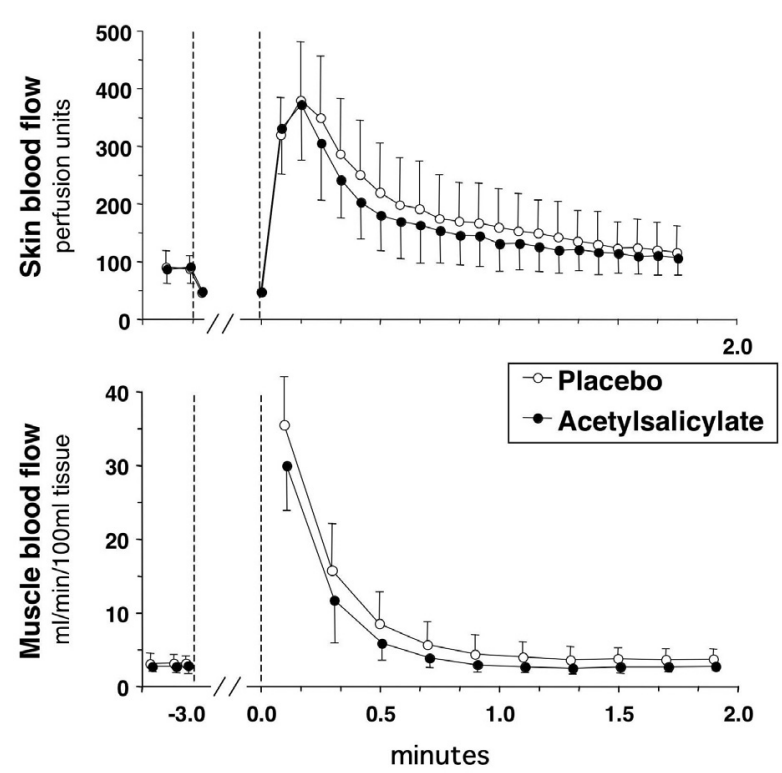

Fig. 3. Time course of reactive hyperemia induced by 3 min of ischemia (dashed vertical lines) in skin and muscle, evaluated in the dominant arm of 7 healthy subjects, following the ingestion of either placebo or acetylsalicylate (1g). Data are means \pm S.D.

with placebo, $\mathrm{p}=0.003$ ). Again, the difference in duration between reactive hyperemia in muscle and skin was significant $(\mathrm{p}=0.01)$, although not affected by acetylsalicylate.

\section{Discussion}

As a transient response of distal vascular beds upon relief of temporary ischemia, reactive hyperemia depends on multiple mechanisms. Metabolic factors, in the form of local accumulation and subsequent washout of vasodilator metabolites such as carbon dioxide, ADP or adenosine, are in all likelihood important, with supporting evidence ranging from response prolongation with increasing duration of ischemia to its partial inhibition by pharmacologic blockade of adenosine receptors (Carlsson et al. 1987). However, there is also strong experimental evidence for the importance of mechanical factors, acting in large part, although not exclusively via the endothelial release of vasodilator mediators (Koller and Kalley 1990b), As recently described in details by Koller and Bagi (2002), such factors could include deformation of endothelial cells when arterioles collapse in the course of flow interruption, as well as their stimulation by stretch and shear stress when reperfusion occurs. Thus, reactive hyperemia might serve as a clinical index of endothelial function, an attractive concept because this vascular

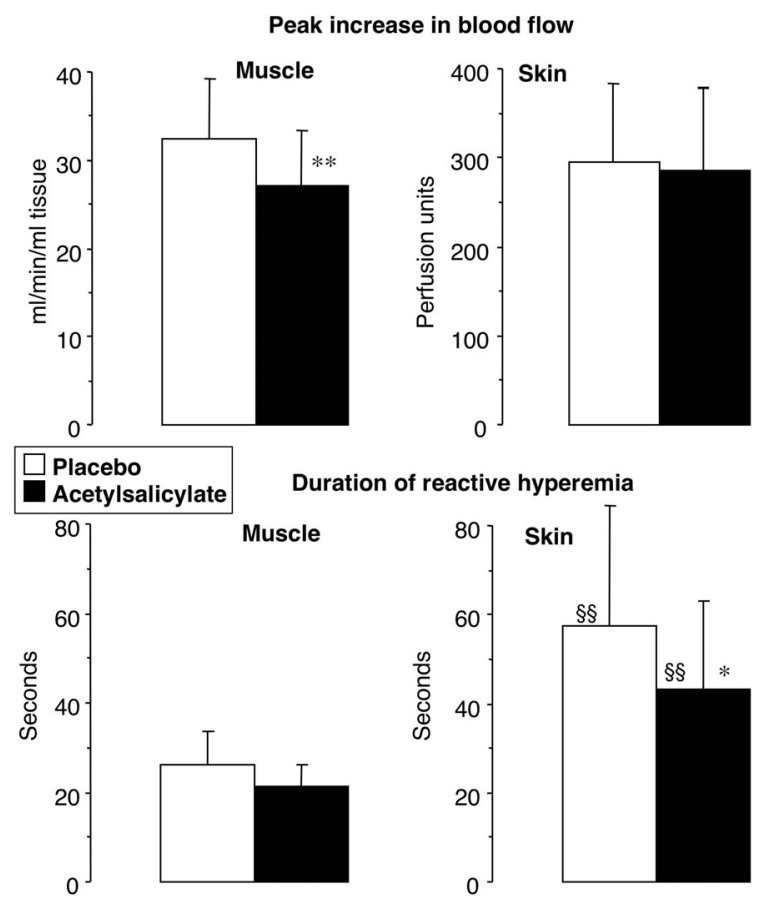

Fig. 4. Summary measures of reactive hyperemia induced by 3 min of ischemia in skin and muscle, evaluated in the dominant arm of 7 healthy subjects, following the ingestion of either placebo or acetylsalicylate $(1 \mathrm{~g}) . * p<0.05, * * p<0.01$ acetylsalicylate vs. placebo. $\S^{\S} \mathrm{p}<0.01$ duration in skin vs. duration in muscle. Data are means \pm S.D.

response can be easily recorded non invasively with the methods used in the present paper. In accordance with this expectation, a tight correlation was found in a mixed population of hypertensive and healthy adults between peak reactive hyperemia in forearm muscle (measured with plethysmography) and the gold standard of endothelial function in humans, namely the response of forearm blood flow to the intrarterial infusion of acetylcholine) (Higashi et al. 2001). Considering this background and the intimate link between endothelial dysfunction and the pathogenesis of cardiovascular disease, it is consistent that reactive hyperemia can track disease progression and cardiovascular risk, as reviewed in the Introduction.

In most of the relevant studies, reactive hyperemia was evaluated in a single forearm, without specification of subject handedness. It makes sense that vascular responses in the skin should be symmetrical, as we indeed verified (Figures 1 and 2), but this assumption is less straightforward in the case of muscle. Carlson et al. (1987) examined 16 healthy subjects of both sexes with plethysmography and found a greater total excess blood flow on the right than on the left forearm $(8.5 \pm 1.4$ vs. $6.8 \pm 1.4 \mathrm{ml} / 100 \mathrm{ml}$ tissue, $\mathrm{p}=0.043)$. In contrast, no 
such difference was reported in a more ancient work (Patterson and Whelan 1955). In none of these two studies was handedness reported. Our results clearly indicate that muscular reactive hyperemia does not systematically differ between the dominant and non dominant forearm.

Available studies have consistently found that reactive hyperemia, as evaluated in the forearm with strain gauge plethysmography, was blunted by pharmacological inhibition of COX. In healthy volunteers, acute reductions in the peak response ranging from 20 to $30 \%$ were reported following acute oral administration of indomethacin $(1.25 \mathrm{mg} / \mathrm{kg}$ ) (Kilbom and Wennmalm 1976, Nowak and Wennmalm 1979), ibuprofen (1.2 g) (Engelke et al. 1996), or acetylsalicylate (2x $30 \mathrm{mg} / \mathrm{kg}$ ) (Carlsson et al. 1983). We essentially reproduced these findings, although the decrease of peak forearm muscle hyperemia observed with $1 \mathrm{~g}$ acetylsalicylate amounted to somewhat less (17\%, Fig. 4) than the $30 \%$ reported by Carlson et al. (1983), who used a much larger dose of the same drug. Thus, the dose of acetylsalicylate chosen in the present study may not have been sufficient to exert a maximal effect on reactive hyperemia in forearm muscle. Nevertheless, we and others have previously shown that $1 \mathrm{~g}$ acetylsalicylate administered orally was able to completely abolish the prostanoid dependent vasodilation induced in the skin by local application of anodal current (Durand et al. 2002, Golay et al. 2004). In forearm skin, this dose of acetylsalicylate had no effect on peak reactive hyperemia but reduced its duration (Figures 3 and 4). This finding must be taken with some caution considering the limited number of subjects in Experiment 2. Nevertheless, it might reconcile apparently discordant results obtained by various authors who did not report the full time course of reactive hyperemia, as evaluated in forearm skin with laser Doppler flowmetry. Moppet et al. (2003) described that the peak response was unaffected by either ibuprofen (800 $\mathrm{mg}$ ) or rofecoxib $(25 \mathrm{mg})$, but provided no information on the later time course. By contrast, while not reporting on the peak response, Bingelli et al. (2003) found a $25 \%$ reduction by acetylsalicylate $(1 \mathrm{~g})$ of postischemic skin blood flow measured after 30-60 s of reperfusion. Similarly, another study describing a depression of skin reactive hyperemia following administration of indomethacin in fact only reports the area under curve of the response (Bisgaard et al. 1986). In finger skin, indomethacin $(1.5 \mathrm{mg} / \mathrm{kg})$ reduced peak reactive hyperemia, which however was measured with finger plethysmography rather than with laser Doppler flowmetry, such that the first $15 \mathrm{~s}$ of the response were missed. Finally, our previous report (Dalle-Ave et al. 2004) that acetylsalicylate did not affect skin reactive hyperemia may have been due to the lower dose used in that study $(0.5 \mathrm{~g})$ in comparison with the present one (1 g).

It is an inherent limitation of plethysmography that it cannot capture the first few seconds of reactive hyperemia, and therefore may miss the actual peak, as most likely occurred in the present study, considering that the apparent maximal blood flow always corresponded to the first data point, obtained between 6 and $9 \mathrm{~s}$ after the release of arterial occlusion (Figures 1 and 3). We therefore cannot infer the impact of acetylsalicylate treatment on the actual maximal post-ischemic muscle blood flow, and neither can any of the aforementioned studies. Whether this actual maximum is resistant to COX blockade, as appears to be the case for peak reactive hyperemia in the skin, could only be resolved by using another methodology for the measurement of muscle blood flow.

The mechanisms which underly the dependence of postischemic vasodilation on prostanoids remain incompletely defined. A non-exhaustive list of possibilities includes the hypoxic activation of phospholipase $\mathrm{A}_{2}$ and consequent release of arachidonic acid from various cell types (Gross et al. 2005), the receptor-mediated stimulation of endothelial COX by the ADP accumulated in the course of ischemia (Boeynaems and Galland 1983), and the non-receptor-mediated stimulation of the same enzyme by hemodynamic forces acting during reperfusion (Koller and Kalley 1990a, Koller et al. 1994).

Reactive hyperemia elicited by $3 \mathrm{~min}$ of forearm ischemia consistently lasted much longer in skin than in muscle (Figures 1-4). To our knowledge, this fact has escaped attention so far, no other study having carried out, as was done here, the concomitant evaluation in both tissues of vascular responses to ischemia of identical durations. One - admittedly simplistic - explanation could be that the oxygen debt incurred with $3 \mathrm{~min}$ of interrupted blood flow is less intense in muscle than it is in skin, due to the presence of myoglobin-bound oxygen in the former.

In summary, our data show that forearm muscle and skin reactive hyperemia do not systematically differ between the dominant and non-dominant side, but may both be blunted by acetylsalicylate. Thus, if these 
responses are to be used as surrogate endpoints in studies of cardiovascular disease, confounding by laterality of measurement need not be feared, but the possible influence of non-steroidal anti-inflammatory drugs must be taken into account. However, the latter restriction might not apply to the peak response in the skin.

\section{Conflict of Interest}

There is no conflict of interest.

\section{Acknowledgements}

The study was supported by departmental funds.

\section{References}

ANDERSSON HI, EJLERTSSON G, LEDEN I, SCHERSTEN B: Impact of chronic pain on health care seeking, self care, and medication. Results from a population-based Swedish study. J Epidemiol Community Health 53: 503$509,1999$.

BINGGELI C, SPIEKER LE, CORTI R, SUDANO I, STOJANOVIC V, HAYOZ D, LUSCHER TF, NOLL G: Statins enhance postischemic hyperemia in the skin circulation of hypercholesterolemic patients: a monitoring test of endothelial dysfunction for clinical practice? J Am Coll Cardiol 42: 71-77, 2003.

BISGAARD H, KRISTENSEN JK, SONDERGAARD J: A new technique for ranking vascular corticosteroid effects in humans using laser-Doppler velocimetry. J Invest Dermatol 86: 275-278, 1986.

BOEGLI Y, GREMION G, GOLAY S, KUBLI S, LIAUDET L, LEYVRAZ PF, WAEBER B, FEIHL F: Endurance training enhances vasodilation induced by nitric oxide in human skin. J Invest Dermatol 121: 1197-1204, 2003.

BOEYNAEMS JM, GALAND N: Stimulation of vascular prostacyclin synthesis by extracellular ADP and ATP. Biochem Biophys Res Commun 112: 290-296, 1983.

CARLSSON I, WENNMALM A: Effect of different prostaglandin synthesis inhibitors on post-occlusive blood flow in human forearm. Prostaglandins 26: 241-252, 1983.

CARLSSON I, LINDE B, WENNMALM A: Arachidonic acid metabolism and regulation of blood flow: effect of indomethacin on cutaneous and subcutaneous reactive hyperaemia in humans. Clin Physiol 3: 365-373, 1983.

CARLSSON I, SOLLEVI A, WENNMALM A: The role of myogenic relaxation, adenosine and prostaglandins in human forearm reactive hyperaemia. J Physiol Lond 389: 147-161, 1987.

COHN JN: Introduction to surrogate markers. Circulation 109 (Suppl IV): IV20-21, 2004.

COHN JN, QUYYUMI AA, HOLLENBERG NK, JAMERSON KA: Surrogate markers for cardiovascular disease: functional markers. Circulation 109 (Suppl IV): IV31-46, 2004.

DALlE-AVE A, KUBLI S, GOLAY S, DELACHAUX A, LIAUDET L, WAEBER B, F. F: Acetylcholine-induced vasodilation and reactive hyperemia are not affected by acute cyclo-oxygenase inhibition in human skin. Microcirculation 11: 327-336, 2004.

DURAND S, FROMY B, BOUYE P, SAUMET JL, ABRAHAM P: Vasodilatation in response to repeated anodal current application in the human skin relies on aspirin-sensitive mechanisms. $J$ Physiol Lond 540: 261-269, 2002.

ENGELKE KA, HALLIWILL JR, PROCTOR DN, DIETZ NM, JOYNER MJ: Contribution of nitric oxide and prostaglandins to reactive hyperemia in human forearm. J Appl Physiol 81: 1807-1814, 1996.

GOLAY S, HAEBERLI C, DELACHAUX A, LIAUDET L, KUCERA P, WAEBER B, FEIHL F: Local heating of human skin causes hyperemia without mediation by muscarinic cholinergic receptors or prostanoids. $J$ Appl Physiol 97: 1781-1786, 2004.

GROSS GJ, FALCK JR, GROSS ER, ISBELL M, MOORE J, NITHIPATIKOM K: Cytochrome P450 and arachidonic acid metabolites: role in myocardial ischemia/reperfusion injury revisited. Circ Res 68: 18-25, 2005.

HIGASHI Y, SASAKI S, NAKAGAWA K, MATSUURA H, KAJIYAMA G, OSHIMA T: A noninvasive measurement of reactive hyperemia that can be used to assess resistance artery endothelial function in humans. Am J Cardiol 87: 121-125, A129, 2001.

HIROOKA Y, IMAIZUMI T, TAGAWA T, SHIRAMOTO M, ENDO T, ANDO S, TAKESHITA A: Effects of Larginine on impaired acetylcholine-induced and ischemic vasodilation of the forearm in patients with heart failure. Circulation 90: 658-668., 1994. 
ISHIBASHI Y, TAKAHASHI N, SHIMADA T, SUGAMORI T, SAKANE T, UMENO T, HIRANO Y, OYAKE N, MURAKAMI Y: Short duration of reactive hyperemia in the forearm of subjects with multiple cardiovascular risk factors. Circ J 70: 115-123, 2006.

KILBOM A, WENNMALM A: Endogenous prostaglandins as local regulators of blood flow in man: effect of indomethacin on reactive and functional hyperaemia. J Physiol Lond 257: 109-121, 1976.

KOLLER A, BAGI Z: On the role of mechanosensitive mechanisms eliciting reactive hyperemia. Am J Physiol 283: H2250-H2259, 2002.

KOLLER A, KALEY G: Prostaglandins mediate arteriolar dilation to increased blood flow velocity in skeletal muscle microcirculation. Circ Res 67: 529-534, 1990a.

KOLLER A, KALEY G: Role of endothelium in reactive dilation of skeletal muscle arterioles. Am J Physiol 259: H1313-H1316, 1990 b.

KOLLER A, SUN D, HUANG A, KALEY G: Corelease of nitric oxide and prostaglandins mediates flow-dependent dilation of rat gracilis muscle arterioles. Am J Physiol 267: H326-H332, 1994.

KUBLI S, WAEBER B, DALLE-AVE A, FEIHL F: Reproducibility of laser-Doppler imaging of skin blood flow as a tool to assess endothelial function. J Cardiovasc Pharmacol 36: 640-648, 2000.

MANCINI GB, DAHLOF B, DIEZ J: Surrogate markers for cardiovascular disease: structural markers. Circulation 109 (Suppl IV): IV22-30, 2004.

MOPPETT IK, DAVIES JA, MAHAJAN RP: Non-selective and cyclo-oxygenase-2-specific non-steroidal antiinflammatory drugs impair the hyperaemic response of skin to brief axillary artery occlusion. Br J Anaesth 91 : 353-356, 2003.

NOWAK J, WENNMALM A: A study on the role of endogenous prostaglandins in the development of exerciseinduced and post-occlusive hyperemia in human limbs. Acta Physiol Scand 106: 365-369, 1979.

PATTERSON G, WHELAN RF: Reactive hyperemia in the human forearm. Clin Sci 14: 197-211, 1955.

PELLATON S, KUBLI S, FEIHL F, WAEBER B: Blunted vasodilatory responses in the cutaneous microcirculation of cigarette smokers. Am Heart J 144: 269-274, 2002.

SANADA M, HIGASHI Y, NAKAGAWA K, TSUDA M, KODAMA I, KIMURA M, CHAYAMA K, OHAMA K: Hormone replacement effects on endothelial function measured in the forearm resistance artery in normocholesterolemic and hypercholesterolemic postmenopausal women. J Clin Endocrinol Metab 87: 46344641, 2002.

ŠKRHA J, PRÁZNÝ M, HAAS T, KVASNIČKA J, KALVODOVÁ B: Comparison of laser-Doppler flowmetry with biochemical indicators of endothelial dysfunction related to early microangiopathy in Type 1 diabetic patients. J Diabetes Complications 15: 234-240, 2001.

TUR E, YOSIPOVITCH G, BAR-ON Y: Skin reactive hyperemia in diabetic patients. A study by laser Doppler flowmetry. Diabetes Care 14: 958-962, 1991.

VUILLEUMIER P, DECOSTERD D, MAILLARD M, BURNIER M, HAYOZ D: Postischemic forearm skin reactive hyperemia is related to cardiovascular risk factors in a healthy female population. J Hypertens 20: 1753-1757, 2002.

WILLIAMS B: Recent hypertension trials: implications and controversies. J Am Coll Cardiol 45: 813-827, 2005.

WU TC, CHEN YH, CHEN JW, CHEN LC, LIN SJ, DING PY, WANG SP, CHANG MS: Impaired forearm reactive hyperemia is related to late restenosis after coronary stenting. Am J Cardiol 85: 1071-1076, 2000. 